\title{
Fostering Soft and Hard Skills for Innovation Among Informatics Engineering Students - an Emancipatory
}

\section{Approach}

\author{
Manuel F. Torres \\ mfirmino@fe.up.pt | Department of Informatics Engineering, Faculty of Engineering University of \\ Porto. INESC TEC - Institute for Systems and Computer Engineering, Technology and Science. Rua \\ Dr. Roberto Frias 4200-465 Porto, Portugal \\ Nuno Flores \\ nflores@fe.up.pt | University of Porto - Faculty of Engineering \& INESC-TEC \\ Raquel T. Torres \\ raquelttorres@gmail.com | Manuel Firmino \& Associados, Lda.
}

\begin{abstract}
Informatics engineers are currently in the spotlight of innovation. It is, therefore, relevant to analyse and reflect on how higher education can, and should, prepare future engineers to innovate as expected in this ever-changing world. This paper aims to further research and foster scholarly debate regarding the requirements and implications of teaching innovation. For that purpose, we examine an exploratory case study on interdisciplinary cooperation between two higher education courses, designed to promote students' active learning of innovation through the progressive development of their soft and hard skills. Both courses engaged in an emancipatory pedagogical approach, mostly grounded in projectbased work, active learning, and formative assessment. To obtain feedback on this interdisciplinary cooperation, questionnaires were devised to ascertain the students' perceptions about this pedagogical approach. Individual responses were collected from both courses and data was analysed through simple statistical procedures. Articulating a priori soft skills development with a posteriori hard skills learning process is perceived by students as beneficial in gradually, yet successfully, understanding the subject of innovation. Also, there were even some external success indicators which showed the recognition of successful innovation skills development in informatics engineering students. Thus, according to students' perceptions of their experience with an emancipatory pedagogy that connected soft with hard skills development, we conclude that such approach encouraged students to create new knowledge and allowed them to develop the necessary skills to innovate.
\end{abstract}

Keywords. Informatics Engineering; Innovation, Soft and Hard Skills; Emancipatory Pedagogy.

Cite paper as: Torres, M., Flores, N., Torres, R., (2020). Fostering Soft and Hard Skills for Innovation Among Informatics Engineering Students - an Emancipatory Approach, Journal of Innovation Management, www.openjim.org, 8(1), 20-38. 


\section{Introduction}

Over the past decades, technological advancements have been shaping the world and changing our lives, allowing innovation to develop at an increasingly fast pace and creating countless opportunities. Currently, technology is widely recognized as a major driver of innovation and, in turn, innovation is considered crucial for professional success.

Many of these technological advances are being made by engineers, putting them into the spotlight of innovation. Informatics engineering, as a domain of knowledge, is at the core of most, every day, technological software applications, ranging from web browsers to very large-scale banking systems. Software is omnipresent in our lives, and we carry it with us everywhere. Specialists and expert professionals are, and have been, in high demand by the industry (EuroStat, 2017), with procurement rates showing no signs of diminishing in the years to come (EuroStat, 2016).

In addition, "the requirements of twenty-first century engineers are considerable: engineers must be technically competent, globally sophisticated, culturally aware, innovative and entrepreneurial, and life-long learners" (Liebenberg \& Mathews, 2012, p. 93). Today, the EUR-ACE ${ }^{1}$ standards and guidelines for accreditation of engineering university degrees define programmes outcomes according to eight learning areas - knowledge and understanding; engineering analysis; engineering design; investigations; engineering practice; making judgements; communication and team-working; and lifelong learning. This recognizes their professional competence as a complex array of knowledge and skills, reaching far beyond technical (also known as hard) skills.

Within this context, and because "educators are further challenged to teach "soft" (social) skills within computing courses" (Exter \& Turnage, 2012, p. 3), Faculty of Engineering University of Porto created Personal and Interpersonal Proficiency course (PIP), addressed at fostering the development of soft skills among undergraduates on a Masters' Degree in Informatics and Computing Engineering ${ }^{2}$. Additionally, this Masters' curriculum includes Software Development Laboratory course (SDL), focused on the improvement of hard technical skills, where students learn to define and apply a software engineering process. In conjunction, both courses are designed, respectively, to promote the development of the soft and hard skills required for academic and professional activity in informatics engineering.

The importance of combining both hard and soft skills together has, for some time now, been demonstrated as a vital component for professional competence (Kauffeld, Grote \& Frieling, 2003). This entails an indissociable interdependence of these competences for the successful performance of future informatics engineers.

Specifically, the need for soft skills is quite evident, considering that, for more than 40 years, the German Engineering Association has recommended that 20\% of all courses in the engineering

$1 \quad$ EUR-ACE accreditation system for quality standards in engineering programmes, which belongs to the European Network for Accreditation of Engineering Education.

2 This is an Integrated Masters' degree program, which results from combining a graduate degree, done in the first three years of university enrollment, and a masters' degree, achieved in the next two years. Thus, these students are called "undergraduates" throughout their enrollment in the Masters' Degree in Informatics and Computing Engineering. 
curricula should be about soft skills. Moreover, "soft skills are behaviours that must be internalized as a natural aspect of a person's repertory of social skills and character attributes" (ODEP 2010 , p. 1), and they are increasingly critical in today's complex business environment. This has led employers to shift their focus towards greater coordination and communication needs from their collaborators, thus giving a greater relevance to soft skills when hiring (Firth, 2011). Hence, to maximize the chances of success for these future informatics engineers, the authors believe that "while professional skills may open the door of opportunity, soft skills keep them in the driver's seat" (Kaipa, Milus, Chowdary \& Jagadeesh, 2005, p. 1).

Interacting with and observing students, the authors discovered that students usually took advantage of a certain continuity between the two mentioned courses, namely in the elaboration of innovation projects. Informally and through their own initiative, several students started using PIP course output as SDL course input, achieving very good results, as they were able to produce more structured and relevant innovation projects but with a lower academic workload. These informal observations encouraged the teachers/authors to: (1) set up a collaboration protocol, focused on boosting students' active learning of innovation, and (2) launch an interdisciplinary supervision based on an emancipatory pedagogical approach, providing stronger on-going support to students. This interdisciplinary cooperation increased the relevance, feasibility, and quality of the innovation projects and, foremost, allowed for students to autonomously develop their knowledge and skills relating to innovation.

The uniqueness of this interdisciplinary cooperation justified an exploratory and descriptive case study to better understand how and why students were so motivated to link soft with hard skills to successfully learn about innovation. The present article introduces and discusses this case study, which sought to systematically ascertain students' perceptions about the impact of this interdisciplinary cooperation on the development of their innovation projects. It serves to help further analyse and reflect about how higher education can, and should, prepare future engineers to innovate, as expected in the professional world. In the following sections, a literature review on innovation and skills is presented, and then a description of the interdisciplinary cooperation protocol, along with the pedagogical approach used. A small-scale study on students' perceptions is presented, and its findings are discussed in order to identify the specific contributions for the research and practice of teaching innovation in informatics engineering higher education programmes. As the aforementioned Master course is, foremost, based on the scientific and technological education of undergraduates, the authors believe that the affordances of this case study will be useful as an example of successful teaching of innovation in a science and technological educational context.

\section{Innovation and skills}

Innovation happens when someone successfully identifies and exploits a new idea (Tether, Mina, Consoli \& Gagliardi, 2005) and "depends on people who are able to generate and apply knowledge and ideas in the workplace and in society at large" (OECD, 2011, p. 9). Today, innovation is a well-known and widely recognized concept. However, it still remains rather complex and controversial, namely when it is linked with entrepreneurship, the latter defined as the generation 
of value by exploiting new products, processes, or markets (Ahmad \& Seymour, 2008). More precisely, "entrepreneurship is a way of thinking, reasoning, and acting that is opportunity obsessed, holistic in approach, and leadership balanced for the purpose of value creation and capture" (Timmons \& Spinelli, 2009, p. 101).

Consequently, over the past decades, many authors have attempted to understand the connection between entrepreneurship and innovation. Some have even referred to these concepts as inextricable, describing entrepreneurs as innovators "who take advantage of change", or entrepreneurship as an "act of innovation". In this context, Zhao (2005) suggested that entrepreneurship and innovation overlapped. Both were positively related, complementary, and equally necessary to succeed. He proposed that innovation is a tool for entrepreneurship to exploit change and that entrepreneurship is the organizational behaviour related to change and innovation. The present paper adopts this approach, perceiving innovation as one of the main drivers of entrepreneurship.

It is also important to highlight that innovation is not automatically produced by scientific and technical knowledge since "some of the crucial elements that 'translate' knowledge into innovation are the ways in which skills and expertise are developed and used by individuals" (Borrás \& Edquist, 2015, p. 215). This perspective is strengthened by the growing emergence of new models of innovation. As explained in the Centre for Research on Innovation and Competition report:

"In the older models of (technological) innovation, such as the 'science push' model of Vannevar Bush, the skills to 'produce' innovation are the degree and higher-level science and engineering skills of a small head or elite in the organisational hierarchy. More recent models of innovation, such as the 'systemic integration' model, allow for more democratic, distributed sources of innovation, involving the skills of the whole workforce. In particular, this model says all workers should have basic 'platform' skills that allow them to be adaptable to changing circumstances and more open to new ideas to be innovative." (Tether et al., 2005, p. 6)

This posed a challenge to the educational system because there is no specific skill set that can ensure innovative performance. Instead, the demand for skills is defined by innovation type and context (OECD, 2011; Tether et al., 2005). This challenge has been increasing alongside the growing concern with the existing "skills mismatch" between education and work (Cinque, 2016; Cobo, 2013; Coll \& Zegwaard, 2006; Quintini, 2011). Innovation is, inevitably, added to the agenda of many prompting political endeavours and international initiatives, focused on aligning the educational supply of skills with labour market demand. Among these initiatives, and together with scientific research, there is a shared perspective of the importance and shortage of soft skills in employability in general, and especially in innovation and entrepreneurship. As stated by Passig and Cohen (2014), "for an organization to realize and execute innovative ideas it needs communication, networking and teamwork skills, as well as motivation" (p. 63), which many organizations find they are lacking.

Soft skills are frequently associated with social, transversal, or generic skills, and, although it is difficult to achieve a clear and simple definition (Cimatti, 2016), they are referred to as "twentyfirst century skills", "key competences" or "skills for social progress" (Cinque, 2016). Additionally, our literature review has shown that it is common (and more helpful) to define soft skills in 
comparison to hard skills. Thus, according to Chell and Athayde (2011), hard skills are based on high levels of expertise relating to specific knowledge and technical content, whereas soft skills are composed of behaviours and attitudes that are acquired through experience. Likewise, Cimatti (2016) describes hard skills as the necessary capacities to perform a particular job and soft skills as the interpersonal skills required at performing all jobs. As such, soft skills can be transversal, and thus, transferable (or applicable) to all contexts and types of innovation, while "give[ing] hard skills the required plasticity to develop and keep up-to-date in changing circumstances" (Cimatti, 2016, p. 99).

Hence, it is not easy to draw a line between soft and hard skills. Even though they are complementary (Borrás \& Edquist, 2015) and both are required to perform a task, its development in an individual is only effective when they are integrated (Cimatti, 2016). Therefore, "it is now common to view cognitive and behavioural skills as complementary with successful individual performance requiring both types of skills" (Coll \& Zegwaard, 2006, p. 32). When addressing innovation and entrepreneurship, these are no exception, as they engage and depend upon both hard and soft skills. Moreover, "successful software development today is therefore as much about the social and team aspect as it is about the process and technology" (Gotel, Scharff \& Kulkarni, 2012, p. 199).

Given the stated commitment to gathering evidence for the aforementioned relationships between soft and hard skills, the authors designed a case study to ascertain these findings in an academic, technological, educational context. This case study relied on a pedagogical methodology focused on promoting the active learning of innovation among informatics engineering students. Through a progressive development of their soft and hard skills, students were able to gradually explore and learn about the complexities of innovation and entrepreneurship, while successfully developing a software product. Aimed at providing an effective engineering education process for innovation, this case study is detailed and analysed in the next section.

\section{Description of the case study}

The case study focused on the establishment of a cooperative protocol between two distinct academic courses. Thus, a single case study is reported here, which is "appropriate when the case is special (in relation to established theory) for some reason. This might arise when the case provides a critical test to a well-established theory, or where the case is extreme, unique, or has something special to reveal" (Rowley, 2002, p. 21). This was an exploratory and holistic case study that "examine[s] the case as one unit" (idem, p. 22) allowing the authors to research a phenomenon that is implicitly indissociable from its specific context (Teegavarapu, Summers \& Mocko, 2008).

This section begins by explaining the details of this protocol, along with the description of the contents and learning objectives of both courses. To support the active learning of innovation, the students were engaged in a common emancipatory pedagogical approach, the framework of which will also be detailed. 


\subsection{Connecting soft and hard skills to boost students' innovation}

As previously stated, innovation is, now more than ever, paramount in informatics engineering. Entrepreneurship and innovation should, thus, play a crucial role in the curriculum of higher education course programmes. As a result, as part of the Master's degree in Informatics Engineering from Faculty of Engineering University of Porto, the promotion of entrepreneurship and innovation is identified as a general goal that should be fostered across course units.As collaboration among course units is encouraged, the Master's programme enabled the required cooperation between PIP and SDL. Enrolled students could, thus, progressively develop the necessary soft and hard skills, towards a successful outcome of their innovation projects.

This cooperation allowed the authors to overcome the traditional division (supported by the literature) between stand-alone approaches (implying the creation of a specific course for the development of innovation skills) and embedded approaches (which entails that these skills should be developed across the curriculum) (MacVaugh, Jones \& Auty 2014; Robley, Whittle \& Murdoch 2005; Simatele 2015). Accordingly, these skills are successfully taught, if integrated and contextualized. This

"means that learners are taught skills in an overt and transparent way that arises out of and is integrated with disciplinary knowledge. Thus, learners are given the opportunity first to understand the skills, and then to enact them in real and meaningful tasks" (MacVaugh, Jones \& Auty, 2014, pp. 768-769).

Likewise, the Accreditation Board for Engineering and Technology (ABET) ${ }^{3}$, endorses in Criterion 5, that the curriculum must culminate in a "major engineering design experience that 1) incorporates appropriate engineering standards and multiple constraints, and 2) is based on the knowledge and skills acquired in earlier course work" (ABET, s/d), promoting thus embedded approaches to curriculum.

The two courses involved in this study are detailed next, followed by a clarification about the pedagogical approach which was adopted to foster the active learning of innovation among informatics engineering students.

\subsection{Personal and Interpersonal Proficiency}

This course aims to prepare students to successfully use their personal and interpersonal skills in informal situations, as well as in academic/professional contexts. The knowledge and skills acquired during this course were organized according to three main areas: personal and professional attitudes (including e.g., micromarketing, time management, creativity); interpersonal attitudes (involving e.g., communication, assertiveness, teamwork); and understanding organizational and societal contexts (entailing e.g., customer service, meetings, team management). The main objectives of this course are:

- To identify and acquire the basic knowledge on how to progressively maximize the successful conditions of the personal and interpersonal performance. 3 ABET is an accreditation system that defines quality standards to uphold within university programs in
science, technology, engineering and mathematics (STEM) in the United States and abroad. 
- To apply self-control techniques and strategies of interpersonal relationships, as to allow a skilful management of (1) the efficient implementation of work processes within an organization and (2) the effectiveness of its outcomes.

- To be aware of the importance of knowing how to use soft skills, and to perform personal growing changes in order to develop a professional profile, thus enhancing the future performance of the informatics engineer.

Teaching soft skills requires the use of several pedagogical methods (expositive, interrogative, demonstrative, and active) and practical activities (case analysis, training exercises, and so on). In these classes, students are grouped into teams and invited to develop an innovation project. The project theme must be constrained to the Master's scope, but should address the student's personal interests, and be applicable in their professional future.

These team projects give students the opportunity to explore some basic principles about innovation and entrepreneurship, ranging from creating innovative hypotheses with added value to organizations, to analysing the relevance/feasibility of the project design/implementation. Such matters are thoroughly debated in class, involving, not only the team members, but all the students and teachers. Discussion focuses on, for example, conditions to generate technologically innovative hypotheses, conceptual aspects and practical procedures on projects development, or possible impact of the projects' application in the social context. This project-base work intends to give, to a heterogeneous group of students, an opportunity to manage a tailored, self-paced development of the set of skills which are required of an innovative engineer. These include, among others, creativity, communication, gathering and analysis of data, information organization and processing, business pragmatism, collaboration/teamwork, time management, and critical thinking.

The development of these projects is also followed-up through team meetings with the course teachers, who "acted as facilitators of the process, and encouraged students to be creative and innovative" (Chang, Benamraoui \& Rieple, 2014, p. 461), thus engaging them in active learning. For this pedagogical approach to be successful, it was necessary to align project-based work and active learning strategies with the adequate formative assessment procedures. This required surpassing "assessment of learning" to invoke also assessment "for and as learning" (Torres \& Leite, 2014). Hence, a strong formative assessment component supported students' elaboration of the innovation projects based not only on teacher assessment, but mostly on peer and selfassessment. Teams were subject to weekly briefings where, together with the rest of the class, they debated and questioned the innovativeness, feasibility and relevance of their projects. This approach creates a favourable environment for continuous peer and self-assessment, and the means to promote feedback, coaching, and critical thinking. Additionally, these briefings served to promote cooperative learning, encouraging students to learn from/with each other and to reach further in solving complex life problems (Cinque, 2016).

It was also a requirement that students must produce two deliverables on their innovation project: (1) a written report and, (2) an oral presentation, supported with audio-visual materials, as a means to enhance students' communication skills (written, oral, and graphical) of complex ideas. Grades were established by combining individual in-class performance with teamwork effort in 
the development of the project and its deliverables. Both deliverables and feedback on the developed innovation projects were later used by students as input for SDL.

\subsection{Software Development Laboratory}

This course unit implies that after completing the three first years of the Master's programme, students have acquired sufficient technological knowledge and theoretical background to cope with the challenge of developing a full-fledged, real life software project. Hence, SDL goal is to allow students to apply a software engineering process that enforces the complete development of a real software system. As an outcome, students should become capable of defining and applying a development process, using agile practices and typical software development tools, while working as a team.

In software engineering, agile practices are a set of lightweight techniques that improve the software process by embracing the relative changing nature of software (Martin, 2013). Nowadays, software changes very rapidly, even during development. Time-to-market is ever decreasing and what stands today may not tomorrow. Therefore, the learned software process must be ready to cope with change, which may come when least expected.

Consequently, software engineers have evolved from adopting a more traditional, waterfall-like, sequential phased process of developing software, towards a more agile, sprint-like, iterative process (Davis, 2012). Software development goes through a series of phases, namely requirements elicitation, design, implementation, testing, and delivery. In a waterfall process, these phases are sequentially executed to completion, where one phase must finish before the next one starts (thus the waterfall analogy). If something changes (e.g., the scope of product changes, errors in the software are found, and so on), it likely forces going back to a previous phase of development. The further back the developer needs to go, the more costly it becomes (Sommerville, 2015).

Due to the increasing volatility of software, the development paradigm has shifted to a more agile process. Instead of handling the full scope of the software product in one single run, the developer divides the scope into smaller minimum viable product partitions, asking the customer to sort them in a most-valuable-sooner fashion. The most valuable scope is then developed first, going through all the phases in a small, fast iteration, where it becomes less costly to incorporate changes that might occur. The final product is, thus, iteratively and incrementally developed to full scope. This partitioning into smaller iterations, and release of a fully functional, partial software product, enables customer feedback sooner and allows for a cost-effective introduction of changes to the software product specifications (Shore, 2007).

Being a course with a strong laboratorial component, its few theoretical classes are used to briefly introduce specific tools or practices that will be used throughout the course and present the overall coordinative structure and role distribution between students and teachers. Most of the laboratory classes, besides project development, are used to monitor progress, review, and improve process quality and to overcome technological obstacles.

The students establish autonomous, self-manageable, self-sustainable working teams that will be responsible for the project development. The teacher, to some extent, supervises the team, 
but they have a considerable degree of liberty to make their own decisions, manage risks, and handle accountability. The team is responsible for planning iterations, setting product goals, distributing member roles, assigning tasks, choosing technologies and tailoring the development process to cope with the project specifics. The iterative nature of the development process allows for a periodic self-assessment of progress. This is done by retrospectively evaluating how the team fared during the previous iteration and on this basis, proposing improvements to uphold in the next iteration. Overall, the project development is divided into five iterations:

- Iteration 0 , week 1 to 5 - this first iteration is termed kick-off. The longer duration comes from bootstrapping the project. Here, existing projects that (eventually) migrate from PIP are matured and converted into software development projects. Activities range from refining requirements with real life customers and stakeholders, to choosing suitable technologies and producing a functional vertical prototype of the final product.

- Iterations 1-4, week 6 to 13 - after week 5, product development starts, divided into twoweek iterations, where the teams are expected to incrementally produce the defined final software product. Process maturity is self-assessed by the teams and monitored by the teachers, as well as project tracking and management.

- Finale, week 14 - by week 14 , the final product is released, and all process related deliverables (source-code, documentation, technical reports, video pitch, and so on) are completed. A public event is held for demonstration of the products, in order to evaluate the idea, concept, and solution from a client's perspective.

These iterations, together with individual assessment and the website of the project/product, are the final graded components. Assessment is conducted throughout the course unit, by presenting the students with a set of specific goals and metrics they should achieve, and upon which they can make self-assessment. In addition, the technological platform for producing and managing the project deliverables allows for continuous feedback in terms of quality and content assessment.

\subsection{An emancipatory approach to innovation in engineering}

Although recognizing the strong interdependency between soft and hard skills, PIP and SDL are very divergent in content, with each mainly focusing on one type of skill. However, these two courses share a common pedagogical approach strongly established upon team project-based work, and sustained on the assumption that "for learning [how] to solve large engineering problems, project work seems to be more suited, because the time-scale and the range of activities of project work more adequately map reality" (Perrenet, Bouhuijs, \& Smits 2000, p. 351). This teaching methodology requires students to learn by doing (Dewey, 1956) and, consequently, to actively engage with innovation, as stated by the literature (Balan \& Metcalfe, 2012; Chang, Benamraoui \& Rieple, 2014; Chang \& Rieple, 2013; Karim, 2016; Pittaway, Hannon, Gibb \& Thompson, 2009; Rasmussen \& Sørheim, 2006).

Additionally, the cooperation between the two courses is driven by a strong concern for the constructive alignment of teaching methods and learning strategies, together with the selected assessment procedures (Biggs, 1999; Torres, 2013), to pursue the intended pedagogical aim of 
guiding students to evolve into knowledge production (via project-based work, active learning, and formative assessment). The authors believe that adopting an emancipatory pedagogical approach may have facilitated students to transpose the produced knowledge and the developed skills from PIP to SDL.

Feedback from students in both classes steered the research towards a more rigorous analysis of the importance of the connection between soft and hard skills in improving the active learning of innovation. It appeared that students enjoyed the soft skills preparation for hard skills development, which, in turn, allowed them to innovate more effectively, and sequentially evolve from idea to project and from project to business (product/service). Encouraged by these findings, a small-scale study was designed to ascertain students' perspectives about this possible advantage of connecting prior soft skills development with hard skills learning, in gradually promoting an innovative competence among engineering students.

\section{Study Design}

This exploratory case study was initially based on the direct observation of students', complemented by documentation analysis. Having insufficient data sources for a more thorough analysis, there was the need for more systematic data collection. Hence, to more rigorously capture students' awareness on the benefits of combining skills from both PIP and SDL courses, a questionnaire survey was developed (based on informally obtained feedback from students), with the intent to present these ideas to all the enrolled students' population. Thus, the devised questionnaire addressed issues regarding the course cooperation, innovative product development, and success metrics. The expected outcome was to ascertain students' perceptions about the benefits brought by the cooperation established between both courses, mainly in terms of innovation and entrepreneurship active learning. This section now details the study and presents the attained results.

\subsection{Participants}

The 2016 population of enrolled students in both courses was approximately 250 students. All students were invited to voluntarily participate in the study, from which a convenience sample of 70 individual responses was obtained.

\subsection{Procedures}

All enrolled students were asked, by email, to answer a short online questionnaire and were informed that all data would remain confidential. Collected responses were analysed through the generation of means and standard deviations. 


\subsection{Instrument}

The questionnaire consisted of three Likert scale items (ranging from 1 - "I completely disagree" to 5 - "I completely agree"), a success metrics question, and a final, free text question. As noted above, these questions were inspired by informal feedback from students, and provided a more rigorous and systematic verification of student perceptions.

\section{Results}

This section presents the results from student answers to the questionnaire. The results are briefly presented and discussed in order to gather evidence for the validation of the initial propositions.

\subsection{Question \#1}

The cooperation between PIP and SDL courses fosters the development of "soft skills" (personal and interpersonal competences) and "hard skills" (software development technical competences) essential to the development of innovation projects.

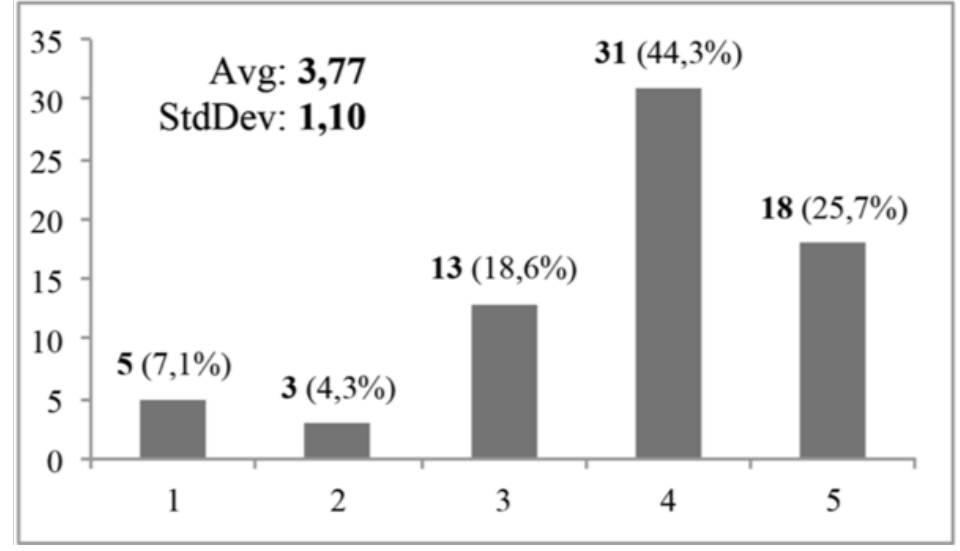

Fig. 1. Question \#1 results.

Question \#1 is quite straightforward, directly asking if the cooperation between PIP and SDL courses is perceived as valuable for the development of innovation projects. As seen in Figure 1, an average rating of 3.77 corroborates the assumption that it is indeed so, as most respondents (70\%) agreed with the presented statement, whereas only a minority (11.4\%) disagreed.

\subsection{Question \#2}

These "soft skills" and "hard skills" are predecessors of innovation and entrepreneurship, in the sense that they promote the ability to evolve an idea towards a project, and a project towards a product. 


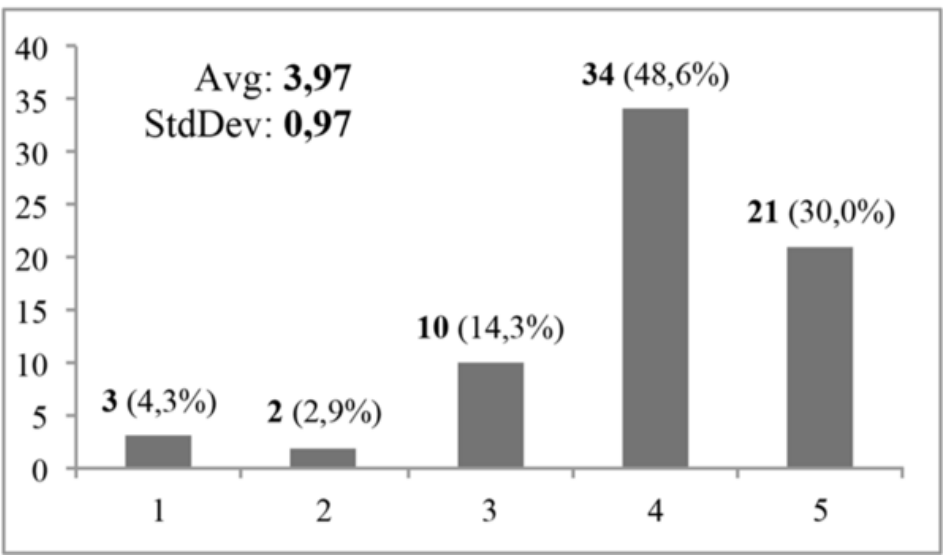

Fig. 2. Question $\# 2$ results.

Question \#2 tried to ascertain if the conjunction of both soft and hard skills is perceived as means to make an innovation project feasible by providing tools to make an idea evolve towards a final product or service. Again, as seen in Figure 2, a meaningful majority of the respondents $(78,6 \%)$ agreed with this statement, whereas a slight minority $(7.2 \%)$ disagreed. The average score of 3.97 substantiates the conclusion that most students perceived this skill combination as valuable for the development of innovation projects.

\subsection{Question \#3}

The sequence of PIP and SDL courses stimulates, first, the improvement of (inter)personal competences - like team work, presentation techniques, critical thinking, and so on - and, second, the application of technologies together with agile software development methodologies, thus assuring the production of quality software. This pedagogical sequence proves indispensable to the materialization of the several innovation projects.

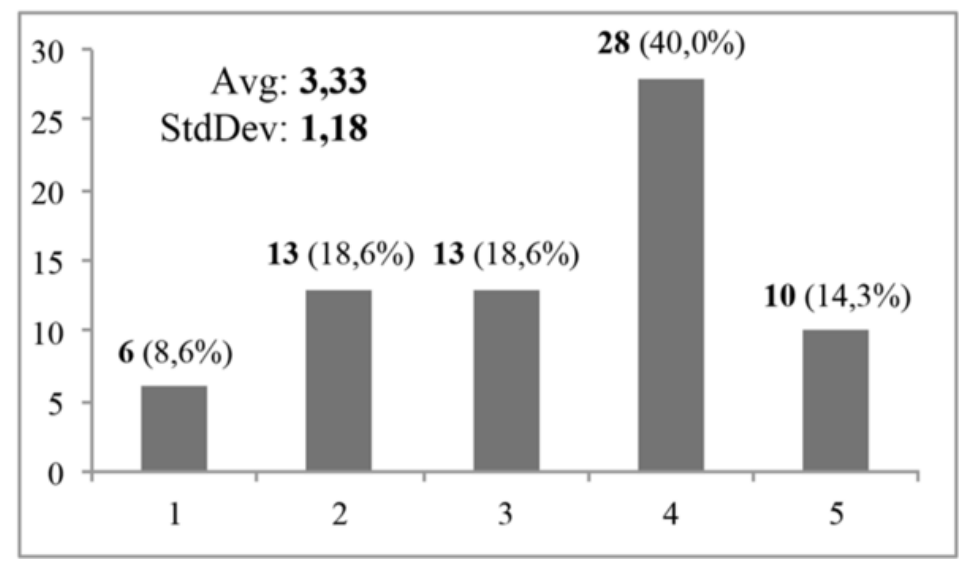

Fig. 3. Question $\# 3$ results.

Question \#3 intended to emphasize the pedagogical sequence between the PIP and SDL courses, addressing the development of soft skills first and hard skills next. It is important to ascertain 
if, beyond the cooperation between the two courses, the sequencing is perceived as appropriate. Figure 3 shows that, although more balanced than the previous questions, most respondents (54.3\%) agreed that the existing sequencing was appropriate and relevant to the effective and sustainable development of innovation projects, while only a minority $(27.2 \%)$ disagreed. The average score of 3.33 supports the premise that students perceived tackling soft skills prior to hard skills as beneficial in coping with the development of innovation projects.

\subsection{Question \#4}

Considering the innovation project(s) in which you have participated, please indicate which success indicators it achieved:

- Commercial interest (CI): buying/acquisition proposal

- Spin-off feasibility (SO): self-investment, third-party investors, incubators, and so on.

- Scientific publication (SP): journal, conference, workshop

- Public recognition (PR): award, merit distinction, media coverage, contests, and so on.

- Release of product/service (RP): incorporation/integration/cooperation with other products/services, donation to institutions, and so on.

- Other success indicators (OS)

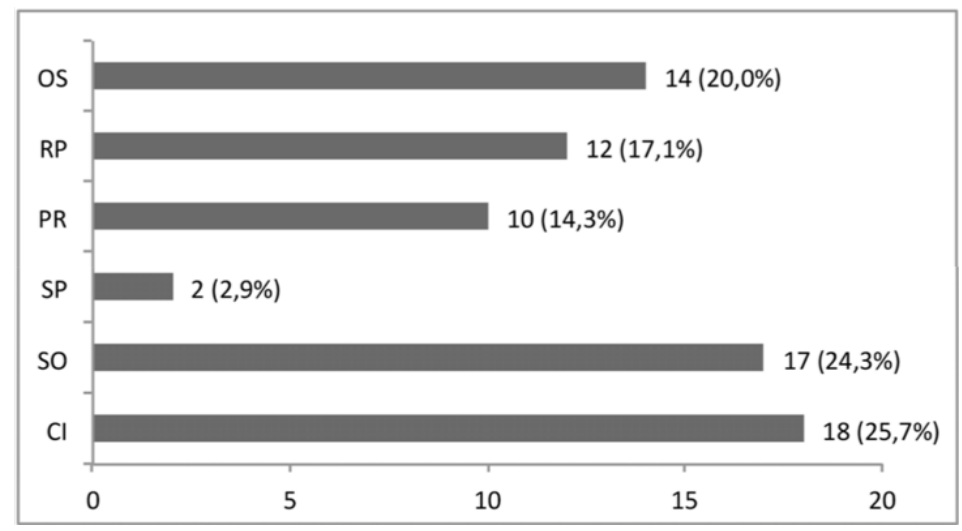

Fig. 4. Question \#4 results.

Question \#4's purpose was to gather data on the level of success achieved by the innovation projects that students were engaged in while attending PIP and SDL courses. Success metrics were divided into six categories, ranging from commercial or investment interest on the product, to public or scientific recognition on the value of the product. As seen in Figure 4, for those projects that had any measure of success, it mostly involved that of commercial interest $(25.7 \%)$ or establishing a business or company to promote/market/evolve the product $(24.3 \%)$. With slightly less predominance but still of relevance, some projects became an integrant part of other larger products or the rights released for public use (17.1\%), while others were awarded for the innovative features or attraction of media attention (14.3\%). These indicators show that the 
success achieved by our students in their innovation projects represent the external recognition of their creative and effective solutions, as well as their authorship.

\subsection{Question \#5}

After concluding both PIP and SDL courses, have you any knowledge of any other innovation project (in either industry or academia) that might have benefited from the skills acquired from these courses? If so, describe it briefly.

Question \#5 intended to sample to what extent the competences acquired during PIP and SDL courses went beyond the context of both courses, and what perceived impact the students had of their value in other projects. Although the number of affirmative responses was low (i.e., ten), most referred to projects developed within another course which was part of the Master's program. In this course, real industry companies and stakeholders "hire" small virtual tech companies, composed only of students, for development of real projects. According to students, this entrepreneurial context benefits greatly from the competences acquired during both PIP and SDL courses, and here, it all combines into, not only a project with real value, but also a full-working start-up company with specific goals and constraints. There were also testimonials which recognized the intrinsic value of these competences, not only in innovation projects, but also throughout the respondents' entire professional careers.

\section{Discussion and conclusions}

Innovation and entrepreneurship are now, indisputably, high-demand competences across most jobs, but particularly informatics engineers are required to "have an entrepreneurial mindset" (Karim, 2016, p. 380). Thus, the challenge of how to teach future engineers to become innovative entrepreneurs seems to rely on how to provide the necessary technical skills without strangling the creativity of students (Mayhew, Simonoff, Baumol, Wiesenfeld \& Klein, 2012). In this case study, the challenge was addressed by creating an interdisciplinary cooperation, inspired by our students' feedback and achievements that focused on the active learning of innovation through a progressive development of soft and hard skills. Throughout the analysis of this exploratory case study, it is possible to outline three main ideas that can enrich the practice of teaching innovation in a science and technological educational context:

(1) It is necessary to recognize that soft skills are essential skills for students' active learning of innovation, namely by allowing them to develop their creativity, autonomy, communication, teamwork and cooperation, self-assessment, critical thinking, and so on. In fact, according to the literature it is imperative to acknowledge that the importance of these transversal skills goes far beyond learning about innovation once that they can even "predict success in life" (Heckman \& Kautz, 2012, p. 452).

(2) This experience showed that, although soft and hard skills can be theoretically taught separately, they are always integrated in practice. So, a cooperative and complementary approach between the development of soft and hard skills was perceived to be most ef- 
fective method to foster innovation among informatics engineering Master's students. As acknowledged by this case study, many students agreed that they enjoyed the soft skill preparation for hard skill development. According to the students, it allowed them to innovate more successfully and sequentially evolve from the idea to project and from the project to business (product/service). The survey data confirmed that connecting prior soft skills development with hard skills learning is perceived by students to be beneficial to their learning process, as they gradually engage in innovation. Also, data analysis produced important indicators (question \#4), showing that, even beyond the context of the courses, some students were recognized as successful innovators. Furthermore, and of importance in future research, these data show that students who benefit from these developed skills continue to apply them in other innovation projects among the Master's curriculum (question $\# 5)$.

(3) This interdisciplinary cooperation, aiming "to meet some of the contemporary demands for knowledge and skills that equip students for addressing the most challenging problems of our time" (Millar, 2016, p. 472), was based on a common pedagogical approach that focused on stimulating students' active learning through project-based work. This allowed students to evolve from a regulatory to a more emancipatory pedagogy. They progressively assumed responsibilities, became more autonomous and learned by doing, which appeared to be crucial in promoting the active learning of innovation among informatics engineering undergraduates.

In conclusion, the complexity of innovating may further benefit from integrative approaches that complement soft with hard skills. There is a pedagogical advantage, as found with this case study, in connecting prior soft skills development with hard skills learning to foster students' active learning of innovation.

Despite the limitations derived from the specificity of the case study design, which is bounded to its own particular context and exploratory procedure, the chosen methodology sought to collect both qualitative and quantitative data so that the resulting findings could inspire other educators to improve their practices by listening to their students and, most importantly, by progressively adopting an emancipatory pedagogical approach. Taking into consideration the students' perceptions and practices was fundamental in further connecting soft with hard skills development. This bond supports students to develop new knowledge and to support them in progressively learning the necessary skills to become capable of innovating in this ever-changing world.

The authors strongly agree that "there is a need to design an educational experience that is timely and engaging for students, yet instrumental in preparing them to be productive members in both the current and future workforce" (Gotel, Scharff \& Kulkarni, 2012, p. 199). This gains even more prominence when considering the existing need in informatics engineering to engage students with innovation and entrepreneurship. We will deeper explore these findings, as it is hoped that the present study will be motivational for further research and trigger more scholarly debate in this area. These debates should address the challenge of educating future science and technological professionals in developing innovation, but, foremost, to emancipate them into becoming responsible, autonomous, and active learners throughout life. 


\section{References}

ABET (n.d.). Criteria for Accrediting Engineering Programs, 2019 - 2020. Accessed $30^{\text {th }}$ October 2019 .

https://www.abet.org/accreditation/accreditation-criteria/criteria-for-accrediting-engineering-programs-2019\#GC5

Ahmad, N., \& Seymour, R. (2008). Defining Entrepreneurial Activity: Definitions Supporting Frameworks for Data Collection (OECD Working Papers). Accessed 12th March 2018: http:// www.oecd.org/officialdocuments/publicdisplaydocumentpdf/?doclanguage $=$ en\&cote $=$ std $/ \operatorname{doc}(2008)$ 1

Balan, P. \& Metcalfe, M. (2012). Identifying teaching methods that engage entrepreneurship students. Education + Training 54(5), 368-384.

Barkas, L. (2011). 'Teaching' or 'support'? The poisoned chalice of the role of Students' Skills Centres. Journal of Further and Higher Education 35(2), 265-286.

Biggs, J. (1999). Teaching for quality learning at university. Buckingham: SRHE and Open University Press.

Borrás, S. \& Edquist, C. (2015). Education, training and skills in innovation policy. Science and Public Policy 42, 215-227.

Chang, J., Benamraoui, A. \& Rieple, A. (2014). Learning-by-doing as an approach to teaching social entrepreneurship. Innovations in Education and Teaching International, 51(5), 459471.

Chang, J. \& Rieple, A. (2013). Assessing students' entrepreneurial skills development in live projects. Journal of Small Business and Enterprise Development, 20(1), 225-241.

Chell, E. \& Athayde, R. (2011). Planning for uncertainty: soft skills, hard skills and innovation. Reflective Practice, 12(5), 615-628.

Cimatti, B. (2016). Definition, development, assessment of soft skills and their role for the quality of organizations and enterprises. International Journal for Quality Research, 10(1), 97-130.

Cinque, M. (2016). Lost in translation. Soft skills development in European countries. Tuning Journal for Higher Education, 3(2), 389-427.

Cobo, C. (2013). Mechanisms to identify and study the demand for innovation skills in worldrenowned organizations. On the Horizon, 21(2), 96-106.

Coll, R. \& Zegwaard, K. (2006). Perceptions of desirable graduate competencies for science and technology new graduates. Research in Science 83 Technological Education, 24(1), 29-58. http://dx.doi:10.1080/02635140500485340

Davis, B. (2012). Agile Practices for Waterfall Projects: Shifting Processes for Competitive Advantage. Florida: J. Ross Publishing.

Dewey, J. (1916). Philosophy of education (Problems of men). California: Littlefield, Adams. 
Eurostat (2016). ICT specialists - statistics on hard-to-fill vacancies in enterprises. Retrieved from EuroStat Statistics. Accessed 13th September 2018: http://ec.europa.eu/eurostat/ statistics-explained/index.php/ICT_specialists_-_statistics_on_hard-to-fill_vacancies_in_enterprises

Eurostat (2017). ICT specialists in employment. Retrieved from EuroStat Statistics. Accessed 13th September 2018: http://ec.europa.eu/eurostat/statistics-explained/index.php/ICT_ specialists_in_employment\#Further_Eurostat_information

Exter, M. \& Turnage, N. (2012). Exploring experienced professional's reflections on computing education. ACM Transactions on Computing Education 12(3), Article 12, 1-23.

Firth, M. (2011) What job skills are employers looking for today? Suite101.com. Accessed 16th January 2018.

http://www.suite101.com/content/what-job-skillsare-employers-looking-for-today-a282039\#ixzz1CWcHpHQy

Gotel, O., Scharff, C. \& Kulkarni, V. (2012). Mixing continents, competences and roles: five years. IET Software, 6(3) 199-213.

Heckman, J. \& Kautz, T. (2012). Hard evidence on soft skills. Labour Economics, 19(4) 451-464. http//dx.doi:10.1016/j.labeco.2012.05.014

Kaipa, P., Milus, T., Chowdary, S. \& Jagadeesh, B. (2005). Soft Skills are Smart Skills. Kaipa Group. Accessed 22th February 2018: http://kaipagroup.com/articles/softskills.pdf

Karim, M. (2016). Entrepreneurship education in an engineering curriculum. Procedia Economics and Finance, 35, 379-387.

Kauffeld, S., Grote, S., \& Frieling, E. (2003). The Kassel Competence Grid (KKR) [The Cassel Competence Grid]. In L. Rosenstiel and J. Erpenbeck (Ed.), Competence Measurement, (pp. 261-281). Stuttgart: Schäffer-Poeschel.

Liebenberg, L. \& Mathews, E. (2012). Integrating innovation skills in an introductory engineering design-build course. International Journal of Technology and Design Education, 22(1), 93-113.

MacVaugh, J., Jones, A., \& Auty, S. (2014) Implicit, stand-alone or integrated skills education for undergraduates: a longitudinal analysis of programme outcomes. Journal of Further and Higher Education, 38(6), 755-772.

Martin, R. (2013). Agile Software Development, Principles, Patterns, and Practices. London: Pearson Education Limited.

Mayhew, M., Simonoff, J., Baumol, W., Wiesenfeld, B., \& Klein, M. (2012). Exploring innovative entrepreneurship and its ties to higher educational experiences. Research in Higher Education, $53(8), 831-859$.

Millar, V. (2016). Interdisciplinary curriculum reform in the changing university. Teaching in Higher Education, 21(4), 471-483.

OECD (2011). Skills for Innovation and Research: Skills for Innovation and Research. Organisation for Economic Co-operation and Development - OECD - Publishing 
Passig, D. \& Cohen, L. (2014). Measuring the style of innovative thinking among engineering students. Research in Science \& Technological Education, 32(1), 56-77.

Perrenet, J., Bouhuijs, P. \& Smits, J. (2000). The Suitability of Problem-based Learning for Engineering Education: Theory and practice. Teaching in Higher Education 5(3), 345-358.

Pittaway, L., Hannon, P., Gibb, A. \& Thompson, J. (2009). Assessment practice in enterprise education. International Journal of Entrepreneurial Behavior \& Research 15(1), 71-93.

Quintini, G. (2011). Right for the Job: Over-qualified or under-skilled? Paris: OECD Working Paper. Accessed 22th March 2018: http://www.oecd.org/els/48650012.pdf

Rasmussen, E. \& Sørheim, R. (2006). Action-based entrepreneurship education. Technovation, $26,185-194$.

Robley, W., Whittle, S. \& Murdoch-Eaton, D. (2005). Mapping generic skills curricula: a recommended methodology. Journal of Further and Higher Education, 29(3), 221-231.

Rowley, J. (2002). Using case studies in research. Management Research News, 25(1), 1627.

Shore, J., \& Warden, S. (2007). The Art of Agile Development: Pragmatic Guide to Agile Software Development. California: O'Reilly Media, Sebastopol.

Simatele, M. (2015). Enhancing the portability of employability skills using e-portfolios. Journal of Further and Higher Education, 39(6): 862-874.

Sommerville, I. (2015). Software Engineering (10th Edition). London: Pearson Education Limited.

Teegavarapu, S., Summers, J. \& Mocko, G. (2008). Case study method for design research: a justification. In Proceedings of the ASME 2008 International Design Engineering Technical Conferences 86 Computers and Information in Engineering Conference, edited by American Society of Mechanical Engineers, 1-9.

Tether, B., Mina, A., Consoli, D. \& Gagliardi, D. (2005). A Literature Review on Skills and Innovation. How Does Successful Innovation Impact on the Demand of Skills and How Do Skills Drive Innovation. Manchester: ESRC Centre for Research on Innovation and Competition. Accessed 12th March 2018: https://www.researchgate.net/publication/268212425

Torres, M. (2013). Modos de trabalho pedagógico e de avaliação da aprendizagem no ensino superior - um estudo na Universidade do Porto (PhD Thesis). Faculdade de Psicologia e de Ciências da Educação, Universidade do Porto, Porto, Portugal. http://repositorio-aberto.up.pt/ handle/10216/67683

Torres, M. \& Leite, C. (2014). Assessment of and for learning in higher education. Transnational Curriculum Inquiry, 11(1), 14-29. http://ojs.library.ubc.ca/index.php/tci/article/view/ 184316

Zhao, F. (2005). Exploring the synergy between entrepreneurship and innovation. International Journal of Entrepreneurial Behavior \& Research, 11(1), 25-41. 


\section{Biographies}
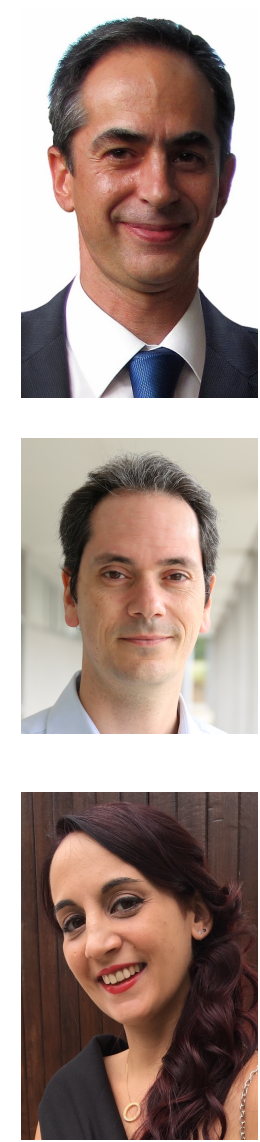

Manuel F. Torres. Manuel Torres is graduated in Psychology and obtained his PhD in Educational Sciences at the University of Porto (UP) with a thesis about Higher Education, one of his main research interests. He was a Professor in higher education since 1983 in several institutions. Currently, he is a Professor at the Faculty of Engineering, UP (FEUP) on Personal and Interpersonal Proficiency, Organizational Behaviour and Project FEUP. He also received several pedagogical recognition awards from FEUP and the pedagogical excellence award from the University of Porto. Additionally, he is Partner Manager of a Consulting Company and Senior Consultant in Psychology, Education and Training at over 150 public and private organizations, with extensive experience in professional and pedagogical training, soft skills development, coaching and counselling.

Nuno Flores. Nuno Flores is an Assistant Professor at Faculty of Engineering of University of Porto (FEUP), lecturing courses on Software Engineering, Agile Software Development and Software Architecture. He's a researcher at the Software Engineering Research Group at FEUP, conducting work aimed at collaborative software knowledge management and software engineering education. He's also a research collaborator at INESC TEC and member of the international Hillside Group. His $\mathrm{PhD}$ thesis is about Software Engineering and his most recent research interests are applying game-like techniques to improve software engineering education.

Raquel T. Torres. Raquel Torres is graduated in Educational Sciences and has a European master degree in Social and Educational Sciences. She has also been enrolled in an interdisciplinary Ph.D. (comprising areas such as sociology, law, economics and politics). Furthermore, she was an education specialist in social and educational institutions and an independent researcher in some universities and research centers, within several study areas. Her research interests include also the development of transdisciplinary approaches to human (inter)actions. Presently, she is a researcher and consultant in a private company, where she is conducting studies about transversal skills in academic and professional contexts. 